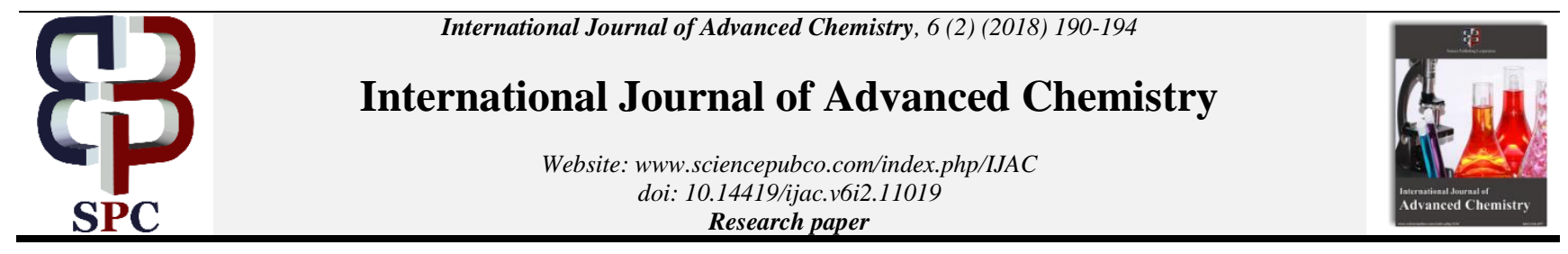

\title{
A semi-empirical estimation of ground and excited state dipole moments of zinc phthalocyanine from solvatochromic shift data
}

\author{
AbimbolaOgunsipe * \\ Department of Chemistry, Federal University of Petroleum Resources Effurun P.M.B 1221, Effurun, Delta State, Nigeria \\ *Corresponding author E-mail:ogunsipe.abimbola@fupre.edu.ng
}

\begin{abstract}
A semi-empirical determination of ground and excited state dipole moments of zinc phthalocyanine (ZnPc) from solvatochromic shifts is hereby presented. The ratio of the excited- and ground-state dipole moments of ZnPc $\left(\frac{\mu_{e}}{\mu_{e}}\right)$ was estimated by a combination of the Bakshiev and the Kawski-Chamma-Viallet's equations, while the difference in the excited- and ground-state dipole moments $(\Delta \mu)$ was estimated usingthe molecular-microscopic solvent polarity parameters $\left(E_{T}^{N}\right)$, alongside the Stokes' shifts $(\Delta \bar{v})$ in the various solvents. The dipole moment of $\mathrm{ZnPc}$ is significantly higher in the excited singlet state $\left(\mu_{\mathrm{e}}=3.12 \mathrm{D}\right)$ than in the ground state $\left(\mu_{\mathrm{g}}=1.50\right.$ D). Obviously charge separation is greater in the excited state of $\mathrm{ZnPc}$ than in its ground state.
\end{abstract}

Keywords:Dipole Moment; Excited State; Ground State; Solvatochromism; Zinc Phthalocyanine.

\section{Introduction}

Phthalocyanine $(\mathrm{Pc})$ is an organic macrocycle that is capable of forming stable complexes with several metals that have extensively found use as blue and green dyes and pigments. Pcs have been utilized in important functional materials in many fields. Apart from their traditional industrial applications, Pcs and their metallated derivatives (metallophthalocyanines, MPcs) have been utilized in many fields such as molecular electronics, optoelectronics, photonics, etc (Kadish et al. 2003, Sakamoto et al. 2004, de la Torre et al. 2004, Cid et al. 2007, Campidelli et al. 2008, Pinzon et al. 2008). The functions of MPcs are almost universally based on electron transfer reactions because of the 18 electron conjugated ring system found in their molecular structure.

MPcs present very interesting electronic properties, and are also very photoactive; this has necessitated investigations into their photophysical and photochemical properties (Ogunsipe et al. 2003, Ogunsipe and Nyokong 2005, Ogunsipe and Nyokong 2011). Most MPc molecules are non-polar because they belong to the $\mathrm{D}_{4 \mathrm{~h}}$ point group; hence there are symmetry operations that take one end of the molecule into the other. Therefore, such molecules will have no dipole along or perpendicular to the symmetry axis. However, features like molecular distortion and ring substitution can induce polarity unto a hitherto non-polar MPc molecule (Kobayashi et al. 1971, Mack and Stillmann 1994). Knowledge of dipole moments is valuable in providing information about the change in the electronic charge distribution upon excitation, assessing parameters like polarizability in non-linear optical materials, understanding the nature of the emitting state, and also in the evaluation of the dielectric friction contribution to the rotational reorientation of polar solutes in solvents (Chandrasekhar et al. 2006).
Many procedures are available for the measurement of ground state dipole moment of a chemical system (Higasi 1953, Aaron et al. 1991); however, there is dearth of techniques for the estimation of the excited state dipole moment. The few available methods for accurate measurement of excited state dipole moment include electro-optical methods like electrochromism of absorption and fluorescent bands (Czekalla 1960), Stark splitting of rotational levels of the 0-0 vibrational bands and the effect of an external electric field on fluorescence anisotropy (Liptay 1974, Bawmann 1989). Nevertheless, these methods are not easily accessible because they involve the use of sophisticated equipment; and also because they might not be applicable to Pcs, MPcs and other large molecules. A convenient method for the estimation of ground and excited state dipole moments is based on the analysis of the solvatochromism of absorption and fluorescence data. This method is easily accessible as it involves only the measurement of absorption and fluorescence maxima, and has been used extensively (Nadaf et al. 2004, Husain et al. 2012) The solvatochromic method is based on a linear correlation between the wave numbers of the absorption and fluorescence maxima and a solvent polarity function which involves both dielectric constant (e) and refractive index (n) of the medium.

The determination of ground and excited state dipole moments of fluorescent organic compounds is well documented (Nadaf et al. 2004, Kabatc et al. 2006, Husain et al. 2012), but there are no reports available in literature on the ground and excited state dipole moments of metallophthalocyanines. This work presents an estimation of the ground and excited state dipole moments of zinc phthalocyanine ( $\mathrm{ZnPc}$, Fig. 1) using the semi-empirical solvatochromic shift method. 


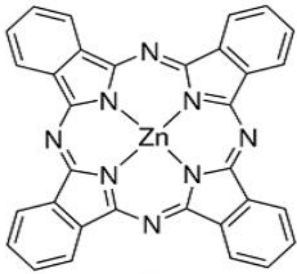

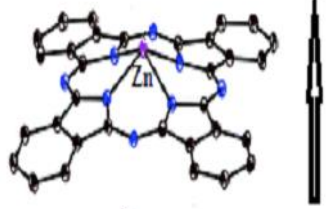

Fig. 1: (A) Structure of Znpc; (B) Structure Showing the Protrusion of Zn Out of the Plane of the Aromatic Ring.

\section{Materials and methods}

\subsection{Materials}

Zinc phthalocyanine $(\mathrm{ZnPc})$ synthesized according to literature procedure (Tomoda et al. 1983). Solvents - trimethylamine, nbutylamine, tetrahydrofuran (THF), dichloromethane (DCM), $\mathrm{N}, \mathrm{N}^{\prime}$-dimethylformamide (DMF), chloroform, dimethylsulphoxide (DMSO), toluene, and benzene were obtained from SAARCHEM; while pyridine, benzonitrile and 1-chlorophthalene were obtained from FLUKA.

\subsection{Equipment}

UV-visible spectra were recorded on a Shimadzu $2550 \mathrm{UV}-\mathrm{Vis}$ spectrophotometer. Fluorescence emission spectra were recorded on a Varian Eclipse spectrofluoremeter.

\subsection{Method}

\subsubsection{Semi-empirical determination of dipole moment}

Ground- and excited-state dipole moments of $\mathrm{ZnPc}$ are determined via a quantitative assessment of solute-solvent interactions (involving the use of solvent-induced spectral shifts, solvent polarity functions and the molecular-microscopic solvent polarity parameter).

The ratio of the excited- and ground-state dipole moments of $\mathrm{ZnPc}$ $\left(\frac{\mu_{\mathrm{e}}}{\mu_{\mathrm{e}}}\right)$ was determined by combining the Bakshiev (Bakshiev 1964) and the Kawski-Chamma-Viallet's (Kawski 1966, Chamma and Viallet 1970) equations. On the other hand, the use of the molecular-microscopic solvent polarity parameter yielded the term $\mu_{\mathrm{e}}-\mu_{\mathrm{g}}$ For polar fluorophores, charge separation is greater in the excited state; therefore, $\mu_{\mathrm{e}}$ is expected to be greater in magnitude than $\mu_{\mathrm{g}}$.

\subsubsection{Bakshiev and kawski-chamma-viallet polarity functions}

Bakshiev and Kawski-Chamma-Viallet equations were obtained from a simple quantum-mechanical second-order perturbation theory. Cognizance was also taken of the Onsager's model.

$\bar{v}_{\mathrm{a}}-\overline{\mathrm{v}}_{\mathrm{f}}=\mathrm{m}_{1} \mathrm{~F}_{1}(\varepsilon, \mathrm{n})+\mathrm{k}_{1} \quad$ (Bakshiev's equation)

$\frac{\bar{v}_{\mathrm{a}}+\overline{\mathrm{v}}_{\mathrm{f}}}{2}=\mathrm{m}_{2} \mathrm{~F}_{2}(\varepsilon, \mathrm{n})+\mathrm{k}_{2}$

(Kawski-Chamma-Viallet's equation)

$\bar{v}_{\mathrm{a}}$ and $\bar{v}_{\mathrm{f}}$ are absorption and fluorescence maximum wavenumbers $\left(\mathrm{cm}^{-1}\right)$, respectively; $\varepsilon$ and $\mathrm{n}$ are the solvent's dielectric constant and refractive index, respectively; $\mathrm{k}_{1}$ and $\mathrm{k}_{2}$ are constants The expressions $\mathrm{F}_{1}(\varepsilon, \mathrm{n})$ and $\mathrm{F}_{2}(\varepsilon, \mathrm{n})$ are defined as:

$\mathrm{F}_{1}(\varepsilon, \mathrm{n})=\left[\frac{\varepsilon-1}{\varepsilon+2}-\frac{\mathrm{n}^{2}-1}{\mathrm{n}^{2}+2}\right]\left[\frac{2 \mathrm{n}^{2}+1}{\mathrm{n}^{2}+2}\right]$

(Bakshiev's polarity function)

$\mathrm{F}_{2}(\varepsilon, \mathrm{n})=\frac{2 \mathrm{n}^{2}+1}{2\left(\mathrm{n}^{2}+2\right)}\left[\frac{\varepsilon-1}{\varepsilon+2}-\frac{\mathrm{n}^{2}-1}{\mathrm{n}^{2}+2}\right]+\left[\frac{3\left(\mathrm{n}^{4}-1\right)}{2\left(\mathrm{n}^{2}+2\right)^{2}}\right]$

(Kawski-Chamma-Viallet's polarity function)

It follows that plots of $\bar{v}_{\mathrm{a}}-\overline{\mathrm{v}}_{\mathrm{f}}$ versus $\mathrm{F}_{1}(\varepsilon, \mathrm{n})$; and $\frac{\overline{\mathrm{v}}_{\mathrm{a}}+\overline{\mathrm{v}}_{\mathrm{f}}}{2}$ versus $\mathrm{F}_{2}(\varepsilon, \mathrm{n})$ should give straight lines. The parameters $\mathrm{m}_{1}$ and $\mathrm{m}_{2}$ occurring in Eqs. 1 and 2 are linear functions of $F_{1}$ and $F_{2}$, and can be determined from the slopes of the straight lines. $\mathrm{m}_{1}$ and $\mathrm{m}_{2}$ are also defined as follows:

$\mathrm{m}_{1}=\frac{2\left(\mu_{\mathrm{e}}-\mu_{\mathrm{g}}\right)^{2}}{\mathrm{hca}^{3}}$

$\mathrm{m}_{2}=\frac{2\left(\mu_{\mathrm{e}}^{2}-\mu_{\mathrm{g}}^{2}\right)}{\mathrm{hca}^{3}}$

$\mathrm{h}$ being Planck's constant, and c, the velocity of light in vacuum. The Onsager's cavity radius (a) of ZnPc is obtained from molecular volume, as given by Suppan's equation:

$a=\sqrt[3]{\frac{3 M}{4 \pi \rho N}}$

Where $\mathrm{M}$ is the ZnPc's molecular weight (577.91 $\left.\mathrm{g} \mathrm{mol}^{-1}\right), \rho$, its density (1.50 $\mathrm{g} \mathrm{cm}^{-3}$ (Gao and Kahn 2002)); and N, the Avogadro's number. From Eq. 7, aZnPc $=5.35 \AA$.

Analysis of Eqs. 5 and 6 yielded the ratio $\frac{\mu_{\mathrm{e}}}{\mu_{\mathrm{e}}}$, given as:

$\frac{\mu_{\mathrm{e}}}{\mu_{\mathrm{e}}}=\frac{\mathrm{m}_{1}+\mathrm{m}_{2}}{\mathrm{~m}_{2}-\mathrm{m}_{1}}$

\subsubsection{Molecular-microscopic solvent polarity parameter $\left(E_{T}^{N}\right)$}

According to Reichardt (Reichardt and Harbusch-Gornert 1983, Reichardt 1994), the molecular-microscopic solvent polarity parameter $\left(E_{T}^{N}\right)$ has dimensionless values that are defined according to Eq. 9. Water and trimethylsilane are taken as extreme polar and non-polar reference solvents, with $\mathrm{E}_{\mathrm{T}}^{\mathrm{N}}$ equal to 1.0 and 0.0 , respectively. All other solvents have values in-between these extreme values.

$E_{\mathrm{T}}^{\mathrm{N}}=\frac{E_{\mathrm{T}}(\text { Solvent })-\mathrm{E}_{\mathrm{T}}(\mathrm{TMS})}{\mathrm{E}_{\mathrm{T}}(\text { Water })-\mathrm{E}_{\mathrm{T}}(\mathrm{TMS})}=\frac{E_{\mathrm{T}}(\text { Solvent })-30.7}{32.4}$

The relationship among Stokes' shift $\left(\bar{v}_{\mathrm{a}}-\bar{v}_{\mathrm{f}}\right)$, the dipole moment difference term $(\Delta \mu)$ and $\mathrm{E}_{\mathrm{T}}^{\mathrm{N}}$ is given by Eq. 10 (Ravi et al. 1994): $\Delta \overline{\mathrm{v}}=\overline{\mathrm{v}}_{\mathrm{a}}-\overline{\mathrm{v}}_{\mathrm{f}}=11307.6\left[\left(\frac{\Delta \mu}{\Delta \mu_{\mathrm{B}}}\right)^{2}\left(\frac{\mathrm{a}_{\mathrm{B}}}{\mathrm{a}}\right)^{3}\right] \mathrm{E}_{\mathrm{T}}^{\mathrm{N}}+$ constant

Where $\Delta \mu$ and $\Delta \mu_{\mathrm{B}}(=9 \mathrm{D})$ are the differences between the excited- and ground-state dipole moments of $\mathrm{ZnPc}$ and betaine, respectively; а and ав are the Onsager cavity radii of $\mathrm{ZnPc}$ and betaine, respectively.

A plot of $\Delta \bar{v}$ against $E_{T}^{N}$ should give a straight light with slope m given as:

$m=139.6\left(\frac{6.2}{a}\right)^{3} \cdot(\Delta \mu)^{2}$

$\Delta \boldsymbol{\mu}$ can then be calculated as:

$\Delta \mu=\sqrt{\frac{m \cdot\left(\frac{6.2}{a}\right)^{-\frac{1}{3}}}{139.6}}$

\section{Results and discussion}

\subsection{UV-visible and fluorescence spectra}

Fig. 2 shows the ground electronic absorption spectra of $\mathrm{ZnPc}$ in five solvents - DMSO, THF, pyridine, triethylamine and 1chloronaphthalene. Solvent parameters - aromaticity, polarity, coordinating power and refractive index, which differ among various solvents are usually used in explaining the observed trend in the variation of Q-band position with solvent. 


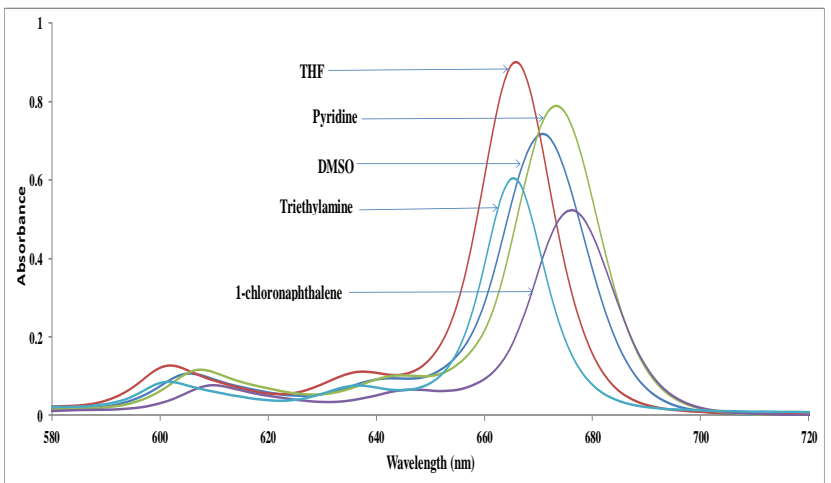

Fig. 2: Ground Electronic Absorption Spectra of Znpc in Five Solvents.

It has been observed that aromatic solvents cause Q-band positions to occur at longer wavelengths (Ogunsipe et al. 2003); this is attributed to the interaction of the $\pi$-electron system of the aromatic solvent with the phthalocyanine ring, which facilitates $\pi$ back-donation, thus augmenting the ring's $\pi$-electron density and therefore destabilizing the highest occupied molecular orbital (HOMO). Consequently, ZnPc's Q-bands occur at longer wavelengths in the aromatic solvents - toluene, benzene, pyridine, benzonitrile and 1-chloronaphthalene (Table 1). In THF however the Q-band exists at $668 \mathrm{~nm}$; the aromatic nature of the solvent is not enough to elicit any further bathochromic shift in Q-band position. This observation suggests that solvent's aromaticity is not sufficient to explain the changes in Q-band position with solvent. Fig. 3 depicts the variation of ZnPc's Q-band positions with the respective solvents' refractive indexes. The wavelength of maximum absorption increases with solvent's refractive index, which is due to the interaction between $\mathrm{ZnPc}$ 's transition-dipole moment and solvent-polarization (Isago et al. 2004).

Table 1:Spectral Data for ZNPC in Various Solvents

\begin{tabular}{|c|c|c|c|c|c|c|}
\hline & $\mathrm{n}$ & $\varepsilon$ & $\mu / \mathrm{D}$ & $\begin{array}{l}\lambda \mathrm{Q} \\
(\mathrm{Abs}) / \mathrm{nm} \\
(\log \varepsilon)\end{array}$ & $\begin{array}{l}\lambda \mathrm{Q} \\
(\mathrm{Ems}) \\
/ \mathrm{nm}\end{array}$ & $\begin{array}{l}\Delta \lambda_{\text {Stokes }} \\
/ \mathrm{nm}\end{array}$ \\
\hline Triethylamine & 1.401 & 2.45 & 0.72 & $666(5.31)$ & 671 & 5 \\
\hline n-butylamine & 1.405 & 4.92 & 1.00 & $669(5.46)$ & 674 & 5 \\
\hline THF & 1.406 & 7.47 & 1.69 & $668(5.48)$ & 672 & 4 \\
\hline *DCM & 1.424 & 9.02 & 1.60 & $671(5.27)$ & 679 & 8 \\
\hline DMF & 1.430 & 37.06 & 3.97 & $670(5.37)$ & 675 & 5 \\
\hline Chloroform & 1.446 & 4.89 & 1.02 & $673(5.29)$ & 680 & 7 \\
\hline DMSO & 1.479 & 46.71 & 3.96 & $672(5.38)$ & 679 & 7 \\
\hline *Toluene & 1.497 & 2.43 & 0.38 & $672(5.32)$ & 676 & 4 \\
\hline *Benzene & 1.501 & 2.274 & 0.00 & $672(5.33)$ & 676 & 4 \\
\hline Pyridine & 1.509 & 13.22 & 2.21 & $674(5.42)$ & 681 & 7 \\
\hline Benzonitrile & 1.528 & 25.20 & 4.28 & $674(5.40)$ & 681 & 7 \\
\hline $1-\mathrm{CN}$ & 1.633 & 5.00 & 1.55 & $677(5.24)$ & 685 & 8 \\
\hline
\end{tabular}

The lack of linearity of Fig. 3 further demonstrates that a combination of solvent parameters is necessary to explicate solvatochromism in $\mathrm{ZnPc}$ and similar complexes.

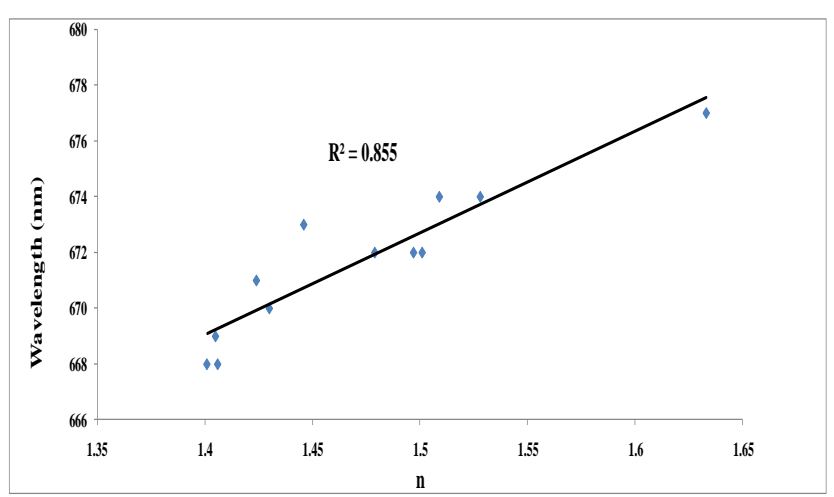

Fig. 3: Dependence of ZNPC'S Q-Band Absorption Position on Solvent's Refractive Index.
Fig. 4 shows the absorption and fluorescence emission spectra of $\mathrm{ZnPc}$ in THF. Stokes' shifts in the various solvents range between 4 and $8 \mathrm{~nm}$. These small Stokes' shifts are due to the rigidity of the chromophore environment that excludes non-fluorescent relaxation to a ground state.

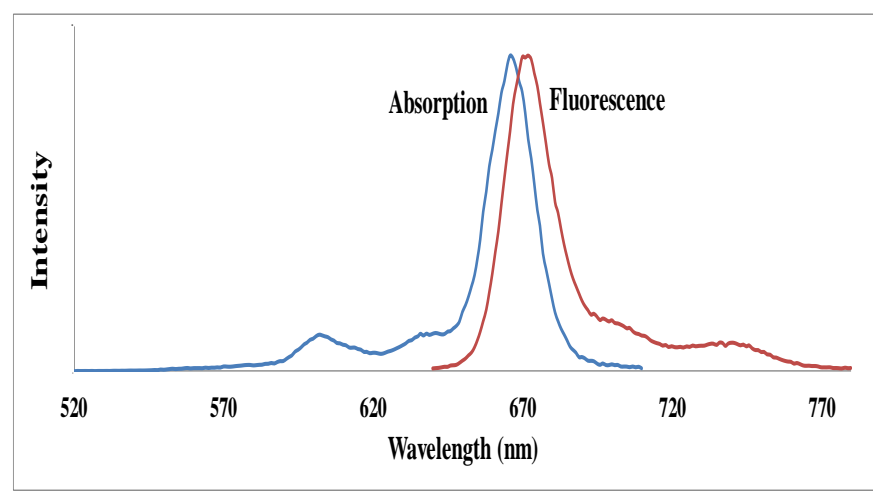

Fig. 4: Absorption and Fluorescence Spectra of $\mathrm{ZnPc}$ in THF.

Plots of polarity functions $\left(\mathrm{F}_{1}\right.$ and $\left.\mathrm{E}_{\mathrm{T}}^{\mathrm{N}}\right)$ against Stokes' shift $(\Delta \overline{\mathrm{v}})$ (Figs. 5 and 7 respectively) and $F_{2}$ against $\frac{\bar{v}_{A}+\bar{v}_{F}}{2}$ (Fig. 6) show linear dependence of the polarity functions on the respective energy functions. However, it must be noted that the most polar solvents and the coordinating solvents in the range (DMF, DMSO, benzonitrile and pyridine, according to dipole moment, $\mu$, values; Table 2) were excluded from the plots; this was due to the failure to obtain linear fits when these solvents were included. It appears that the polarity functions $\mathrm{F}_{1}, \mathrm{~F}_{2}$ and $\mathrm{E}_{\mathrm{T}}^{\mathrm{N}}$ do not adequately account for the high polarities of these solvents, as observed before (Ogunsipe 2018). Again, it appears that specific fluorophoresolvent interactions such as dipole-dipole interactions or electronpair Donor/electron-pair acceptor interactions also contribute significantly to the overall solute-solvent interaction.

Table 2: Solvatochromic Data for the Determination of ZnPc's Ground State and Excited State Dipole Moments

\begin{tabular}{|c|c|c|c|c|c|}
\hline & $\mathrm{F}_{1}$ & $\mathrm{~F}_{2}$ & $E_{T}^{N}$ & $\begin{array}{l}\left(\bar{v}_{\mathrm{a}}-\bar{v}_{\mathrm{f}}\right) \\
/ \mathrm{cm}^{-1}\end{array}$ & $\left(\overline{\mathrm{v}}_{\mathrm{a}}+\overline{\mathrm{v}}_{\mathrm{f}}\right) / \mathrm{cm}^{-}$ \\
\hline Triethyamine & 0.1030 & 0.3240 & 0.259 & 112 & 14959 \\
\hline n-Butylamine & 0.4002 & 0.4752 & 0.762 & 111 & 14892 \\
\hline Dichloromethane & 0.5932 & 0.5843 & 0.111 & 176 & 14815 \\
\hline Chloroform & 0.3774 & 0.4909 & 0.386 & 153 & 14782 \\
\hline Toluene & 0.0390 & 0.3549 & 1.00 & 88.1 & 14837 \\
\hline Benzene & 0.0045 & 0.3403 & 0.654 & 88.1 & 14837 \\
\hline
\end{tabular}

$\mathrm{m}_{1}=153.75 ; \mathrm{m}_{2}=438.16 ; \mathrm{m}=386.66 ; \frac{\mu_{e}}{\mu_{g}}=2.08 ; \Delta \mu=1.62 \mathrm{D} ; \mu_{\mathrm{g}}$ $=1.50 \mathrm{D} ; \mu_{\mathrm{e}}=3.12 \mathrm{D}$

\subsection{Zinc phthalocyanine structure and dipole moment}

The geometry of the nuclear skeleton of a metallophthalocyanine is almost perfectly square planar with a $\pi$-electron system of $\mathrm{D}_{4 \mathrm{~h}}$ symmetry comprising of a $\mathrm{C}_{4}$ principal axis of rotation, four perpendicular $\mathrm{C}_{2}$ axes and a horizontal mirror $(\sigma \mathrm{h})$ plane (Fig. 1a); and this should confer an almost zero dipole moment on the molecule. However, some metals do not perfectly fit into the phthalocyanine $(\mathrm{Pc})$ cavity, in which case the symmetry drops to $\mathrm{C}_{4 \mathrm{v}}$. In $\mathrm{ZnPc}$, there are four vertical mirror $\left(\sigma_{\mathrm{v}}\right)$ planes in addition to the $\mathrm{C}_{4}$ axis. Zinc is displaced $45 \mathrm{pm}$ from the plane of the aromatic ring, with $\mathrm{Zn}-\mathrm{N}$ bond lengths of $206.1 \mathrm{pm}$, to form a domed shape (Kobayashi et al. 1971, Mack and Stillmann 1994) (Fig. 1b). The drop in symmetry from $\mathrm{D}_{4 \mathrm{~h}}$ to $\mathrm{C}_{4 \mathrm{v}}$ in the $\mathrm{ZnPc}$ molecule should be responsible for its observed polarity. Even in the $\mathrm{C}_{4 \mathrm{v}}$ symmetry, the molecule cannot have a component of the dipole moment perpendicular to the symmetry axis $\left(\mathrm{C}_{4}\right)$, because a dipole moment which exists in one direction perpendicular to the axis is cancelled by an opposing dipole. A dipole moment in these molecules can only be parallel to the molecular axis (Fig. 1b). 
The treatment of solvatochromic data in this work, which is based on the plots involving the polarity functions $\left(\mathrm{F}_{1}\right.$ vs $\Delta \overline{\mathrm{v}}, \mathrm{F}_{2}$ vs $\frac{\overline{\mathrm{v}}_{A}+\overline{\mathrm{v}}_{F}}{2}$, and $\left.\mathrm{ET}^{\mathrm{N}} \mathrm{vs} \Delta \overline{\mathrm{v}}\right)$, and their respective slopes ( $\mathrm{m}_{1}, \mathrm{~m}_{2}$ and $\mathrm{m}$, Figs. 5 , 6 and 7 respectively), culminated in the values of ground state and excited state dipole moments of $\mathrm{ZnPc}$.

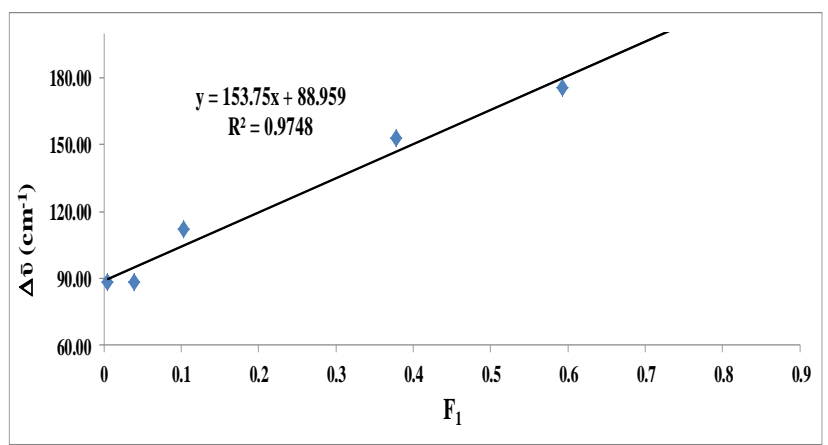

Fig. 5: Dependence of Znpc'sstokes' Shift on the Bakshiev'sSolvent Polarity Function $\left(\mathrm{F}_{1}\right.$, Eq. 3)

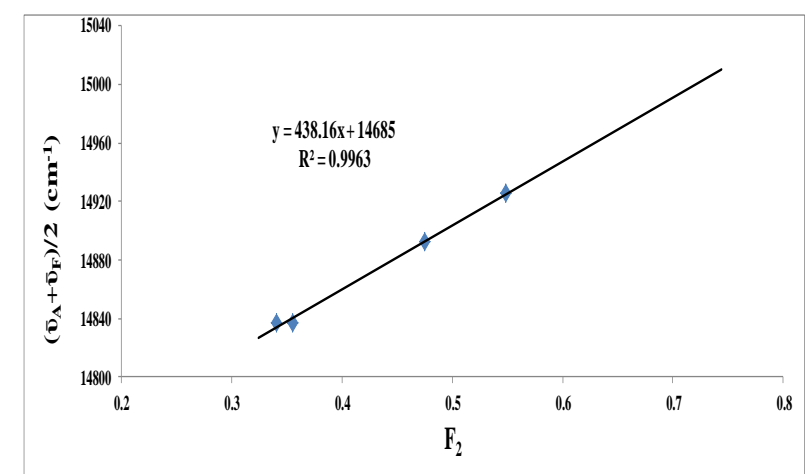

Fig. 6:Dependence of Znpc'sabsorption/Fluorescence Wavenumber on the Kawski-Chamma-Viallet'sSolvent Polarity Function ( $F_{2}$, Eq. 4).

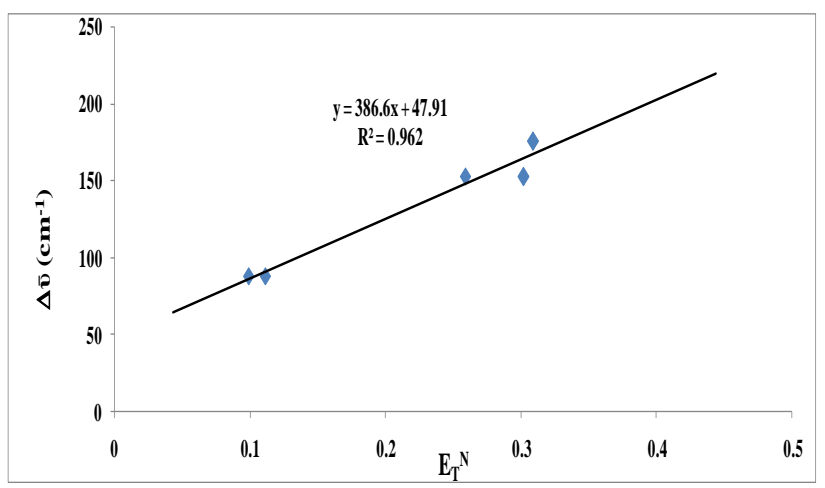

Fig. 7: Dependence of ZnPc's Stokes' shift on the molecular-microscopic solvent polarity parameter $\left(\mathrm{E}_{\mathrm{T}}^{\mathrm{N}}\right.$, Eq. 5$)$.

The respective values of $\mathrm{m}_{1}$ and $\mathrm{m}_{2}$ and $\mathrm{m}$ were found to be 153.75 , 438.16 and $386.66 \mathrm{~cm}^{-1}$, respectively; which resulted in the following values: $\Delta \tilde{v}=1.62 \mathrm{D}$ and $\frac{\mu_{e}}{\mu_{g}}=2.09 \mathrm{D}$. The values of ground state and excited state dipole moments were then calculated to be $\mu_{\mathrm{g}}=1.50 \mathrm{D}$, and $\mu_{\mathrm{e}}=3.12 \mathrm{D}$ (Table 2). As expected, $\mathrm{ZnPc}$ is more polar in the excited state than in the ground state which, is attributed to a modification of electronic charge distribution in the excited singlet state relative to the ground state (altered charge separation upon excitation).

\section{Conclusion}

The dipole moment of $\mathrm{ZnPc}$ is significantly higher in the excited singlet state $\left(\mu_{\mathrm{e}}=3.12 \mathrm{D}\right)$ than in the ground state $\left(\mu_{\mathrm{e}}=1.50 \mathrm{D}\right)$, indicating a substantial redistribution of the $\pi$-electron densities in the more polar excited state. The most polar solvents and the co- ordinating solvents were left out of the plot leading to the estimation of the dipole moments. It appears that specific fluorophoresolvent interactions such as dipole-dipole interactions or electronpair

Donor/electron-pair acceptor interactions also contribute significantly to the overall solute-solvent interaction. It is worthwhile to stress that the solvatochromic shift method might not be as accurate as instrumental methods, due to approximations and oversimplifications made in the method. However, the method remains very convenient because it negates the use of expensive equipment and is easily accessible.

\section{Acknowledgement}

AO thanks Prof Tebello Nyokong of Rhodes University, South Africa, for the use of her facilities.

\section{References}

[1] Aaron JJ, Tine A, Gaye MD, Parkanyi C, Boniface C \&Bieze TWN (1991) Effects of solvent on the electronic absorption and fluorescence spectra of quinazolines, and determination of their ground and excited singlet-state dipole moments. Spectrochimica Acta Part A: Molecular $\quad$ Spectroscopy 47A, 419 430.https://doi.org/10.1016/0584-8539(91)80119-4.

[2] Bakshiev NG (1964) Universal intermolecular interactions and their effect on the position of the electronic spectra of molecules in two component solutions. Optics and Spectroscopy 16, 821-832.

[3] Baumann W (1989) Physical Methods of Chemistry (Rossiter BW \& Hamilton JF eds.), John Wiley and Sons, New Jersey, Vol. 38, p. 45

[4] Campidelli S, Ballesteros B. Filoramo A, Diaz D, De la Torre G, Torres T, Rahman GMA, Aminur EC, Kiessling D, Werner F, Sgobba V, Guldi DM, Cioffi C, Prato M \&Bourgoin J-P (2008) Facile Decoration of Functionalized Single-Wall Carbon Nanotubes with Phthalocyanines via "Click Chemistry. Journal of American Chemical Society 130, 1150311509.https://doi.org/10.1021/ja8033262.

[5] Chamma A \&Viallet P (1970) De'termination du moment dipolaired'une molecule dansUNe'tat excite singulet $\mathrm{L}$ application a' l'indole, au benzimidazoleET a' l'indazole. ComptesRendus de Académie des Sciences - Series C - Chemistry 270, 1901-1904.

[6] Chandrasekhar K, Naik LR, Suresh HM \& Math NN (2006) Steady-state absorption and fluorescence study: Dipole moments of coumarins. Indian Journal of Pure and Applied Physics 44, 292-299.

[7] Cid J-J, Yum J-H, Jang S-R, Nazeeruddin MK, Martinez-Ferrero E, Palomares E, Ko J, Graetzel M \& Torres T (2007) Molecular Cosensitization for Efficient Panchromatic Dye-Sensitized Solar Cells. Angewandte Chemie International Edition 46, 83588362.https://doi.org/10.1002/anie.200703106.

[8] Czekalla J (1960) Elektrischefluoreszenzpolarisation: die bestimmung von dipolmomentenangeregtermoleküleausdemfolarisationsgrad der fluoreszenz in starkenelektrischenfeldern. ZeitschriftfürElektrochemie 64, 1221-1228.

[9] De la Torre G, Vazquez P \& Torres T (2004) Role of structural factors in the nonlinear optical properties of phthalocyanines and related compounds. Chemical Reviews 104, 3723 3750.https://doi.org/10.1021/cr030206t.

[10] Gao W \& Kahn a (2002) Electronic structure and current injection in zinc phthalocyanine doped with tetrafluorotetracyanoquinodimethane: Interface versus bulk effects. Organic Electronics 3, 5363.https://doi.org/10.1016/S1566-1199(02)00033-2.

[11] Higasi K (1953) the Dipole Moments of Fluorenone Peroxide and Bishydroperoxide. Bulletin of the Chemical Society of Japan 39 248-250.https://doi.org/10.1246/bcsj.26.248.

[12] Husain MM, Sindhu R \&Tandon HC (2012) Photophysical properties and estimation of ground and excited state dipole moments of 7-diethylamino and 7-diethylamino-4-methyl coumarin dyes from absorption and emission spectra. European Journal of Chemistry 3, 87-93.https://doi.org/10.5155/eurjchem.3.1.87-93.519.

[13] Isago H, Kagaya Y \& Matsushita a (2004) Solvatochromic Shift of Phthalocyanine Q-band Governed by a Single Solvent Parameter. Chemistry Letters 33, 862-863.https://doi.org/10.1246/cl.2004.862.

[14] Kabatc J, Osmialowski\&Paczkowski J (2006) the Experimental Studies on the Determination of the Ground and Excited State Di- 
pole Moments of Some Hemicyanine Dyes. SpectrochimicaActa Part A 63, 524-531.https://doi.org/10.1016/j.saa.2005.05.039.

[15] Kadish KM, Smith KM \& and Guilard R (2003) the Porphyrin Handbook, Volumes 15-20. Academic Press, San Diego CA.

[16] Kawski A (1966) Der wellenzahl von elektronenbandenlumineszie - rendenmolekille. ActaPhysicaPolonica 29, 507-518.

[17] Kobayashi T, Ashida, T, Uyeda N, Surro E \&Kakuda M (1971) The crystal structure of the 2:3 complex of zinc phthalocyanine and nhexylamine. Bulletin of the Chemical Society of Japan 44, 20952103.https://doi.org/10.1246/bcsi.44.2095.

[18] Liptay W (1974) Excited States (Lim EC ed.), Academic Press, INC New York, Vol. 1, pp. 129-229.

[19] Mack J. \&Stillman MJ (1994) Photochemical formation of the anion radical of zinc phthalocyanine and analysis of the absorption and magnetic circular dichroism spectral data - Assignment of the optical spectrum of $[\mathrm{ZnPc}(-3)]-$. Journal of American Chemical Society 116, 1292-1304.https://doi.org/10.1021/ja00083a015.

[20] Nadaf YF, Mulimani BG, Gopal M \&Inamdar SR (2004) Ground and excited state dipole moments of some exalite UV laser dyes from solvatochromic method using solvent polarity parameters Journal of Molecular Structure (Theochem) 678, 177181.https://doi.org/10.1016/j.theochem.2004.01.049.

[21] Ogunsipe A, Maree D \&Nyokong T (2004) Solvent effects on the photochemical and fluorescence properties of zinc phthalocyanine derivatives. Journal of Molecular Structure 650, 131-140, https://doi.org/10.1016/S0022-2860(03)00155-8.

[22] Ogunsipea\&Nyokong T (2005) Photophysical and photochemical studies of non-transition metal phthalocyaninesulphonates in aqueous and non-aqueous media. Journal of Photochemistry Photobiol$\begin{array}{llll}\text { ogy } & \text { A: } & \text { Chemistry } & 173,\end{array}$ https://doi.org/10.1016/j.jphotochem.2005.03.001.

[23] OgunsipeA\&Nyokong T (2011) Solvent Effects on the photophysicochemical properties of tetra (tertbutylphenoxy)phthalocyaninatozinc (II). ActaPhysicochimicaSinica 27, 1045-1052.

[24] Ogunsipe A (2018) Solvent effects on the spectral properties of Rhodamine 6G: Estimation of ground and excited state dipole moments. Journal of Solution Chemistry 47, 203219.https://doi.org/10.1007/s10953-017-0706-8.

[25] Pinzon JR, Plonska-Brzezinska ME, Cardona CM, Athans AJ, Gayathri SS, Guldi DM, Herranz MA, Martin N, Torres T \&Echegoyen L (2008) Sc3N@C80-Ferrocene electrondonor/acceptor conjugates as promising materials for photovoltaic applications. Angewandte Chemie International Edition 47, 41734176.https://doi.org/10.1002/anie.200800473.

[26] Ravi M, Samanta A \&Radhakrishnan TP (1994) Excited state dipole moments from an efficient analysis of solvatochromic stokes shift data. Journal of Physical Chemistry 98, 91339136.https://doi.org/10.1021/j100088a007.

[27] Reichardt C \&Harbusch-Gornert E (1983) Überpyridinium-N-phenolat-betaine und ihreverwendungzurcharakterisierung der polarität von lösungsmitteln, X. Erweiterung, korrektur und neudefinition

ET-lösungsmittelpolaritätsskalamithilfeeineslipophilen penta-tert-butyl-substituiertenpyridinium- $\mathrm{N}$-phenolat-betainfarbstoffes. Liebigs Annalen der Chemie 721743.https://doi.org/10.1002/jlac.198319830502.

[28] Reichardt C (1994) Solvatochromic dyes as solvent polarity indicators. Chemical Reviews 94, 23193458.https://doi.org/10.1021/cr00032a005.

[29] Sakamoto K, Okumura E and Hirohashi R (2004) Phthalocyanine as functional dyes. IPC, Tokyo.

[30] Tomoda H, Saito S \&Shiraishi S (1983) Synthesis of metallophthalocyanines from phthalonitrile with strong organic bases. Chemistry Letters 313-316.https://doi.org/10.1246/cl.1983.313. 